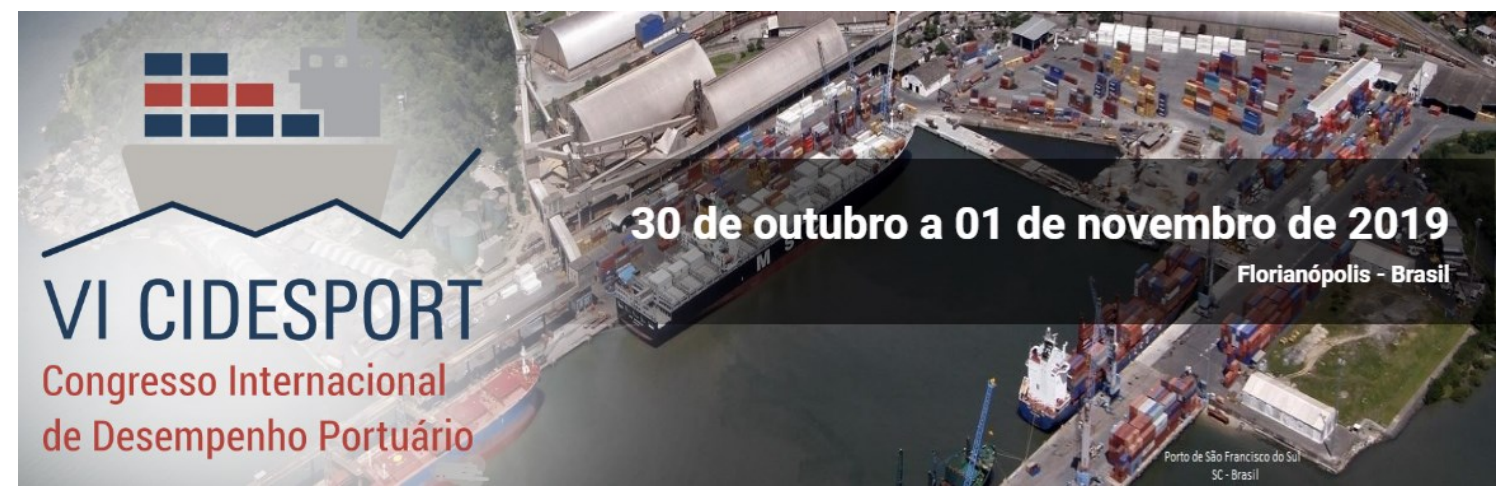

\title{
A CONSOLIDAÇÃO DAS REVITALIZAÇÕES PORTUÁRIAS NA EVOLUÇÃO DA RELAÇÃO PORTO-CIDADE: OS PRINCIPAIS ASPECTOS NO BRASIL E NO MUNDO
}

\author{
Aleph Tonera Lucas \\ Universidade Federal de Santa Catarina
}

Ana Luiza Shimomura Spinelli

Universidade Federal de Santa Catarina

Luísa Siqueira Doebeli

Universidade Federal de Santa Catarina

Maria Eduarda I. Arruda

Universidade Federal de Santa Catarina

Tiago Buss

Universidade Federal de Santa Catarina

\begin{abstract}
Resumo: A evolução da relação porto-cidade aponta as revitalizações portuárias como o estágio mais atual de relação entre os espaços portuários e urbanos. Para compreender a reintegração de áreas portuárias à cidade, é relevante a compreensão dos principais aspectos de consolidação desses projetos, assim como para a interpretação deste fenômeno no contexto brasileiro, e direcionamento futuro para o processo de tomada de decisão ex-ante da sua implantação. Neste artigo foram avaliados os principais aspectos das revitalizações portuárias, considerando projetos no Brasil e no mundo já implantados. Foram comparadas as relações entre os projetos identificados, em seu grau de planejamento, estrutura operacional, parcerias públicas e privadas, assim como identificando os sucessos e insucessos destas experiências. Como objetivo atendido no trabalho, tem-se a identificação, com base na pesquisa bibliográfica sistêmica, de quais os principais aspectos para avaliação de revitalizações portuárias enquanto Grandes Projetos Urbanos.
\end{abstract}

Palavras-chave: Revitalização portuária. Revitalização urbana. Relação portocidade. Grandes projetos urbanos.

\section{INTRODUÇÃO}

A temática de revitalizações em portos vem ganhando espaço entre os planejadores nos últimos anos, o que indica a sua relevância para a revolução da relação porto-cidade em municípios portuários. A análise dos aspectos comuns a intervenções desta categoria, bem como aqueles relacionados ao sucesso ou insucesso de experiências já implantadas, torna-se um importante

* A revisão gramatical, ortográfica, ABNT ou APA foi realizada pelos autores. 
meio de direcionamento para novos projetos, e da tomada de decisão de planejamento mais assertivas para futuras implantações.

Neste contexto, o presente trabalho tem como objetivo geral avaliar o processo de consolidação de projetos de revitalizações portuárias, observando o âmbito internacional e nacional, segundo os principais aspectos de avaliação propostos pela bibliografia da área, evidenciando a evolução da relação portocidade propiciada por tais intervenções, a fim de direcionar possibilidades para tomada de decisão ex-ante.

Como objetivos específicos para atendimento do objetivo geral proposto, constam: indicar, com base na bibliografia, quais os principais aspectos para avaliação de projetos de revitalizações portuárias enquanto Grandes Projetos Urbanos; pesquisar as principais experiências de revitalizações portuárias no mundo, e seu enquadramento nos aspectos indicados pela bibliografia como essenciais para a sua análise, sucesso e insucesso; e caracterizar as revitalizações portuárias brasileiras já realizadas sob os mesmos aspectos analisados nas experiências internacionais.

Os objetivos se enquadram em uma visão de avaliação estratégica no ambiente portuário, dando ênfase nas temáticas de formulação e implementação de estratégias para o desenvolvimento portuário, buscando qualificar a relação porto-cidade, assim como investigar e promover conhecimento relacionado a estratégias de sustentabilidade socioambiental para o setor.

\section{REFERENCIAL TEÓRICO}

O referencial teórico foi desenvolvido com foco em três principais temáticas pesquisadas, sendo elas: a caracterização do entendimento da relação porto-cidade e a relevância das revitalizações portuárias; assim como no estabelecimento dos principais aspectos a serem considerados no processo de consolidação das revitalizações portuárias. As principais fontes de pesquisa foram os planejamentos portuários realizados nos principais portos do Brasil e no Mundo, que tiveram algum tipo de revitalização ou possuem projetos para tal, assim como em artigos científicos que relatam casos de sucesso ou insucesso sobre o tema.

\subsection{As revitalizações portuárias e a evolução da relação porto-cidade}

A relação entre as cidades e os portos existe desde o início do surgimento dos espaços urbanos, e da consolidação das cidades enquanto os núcleos centrais para as relações sociais e econômicas. Foi a partir da navegação de longo curso, que a colonização se dispersou e teve início a integração dos mercados em nível global, bem como o surgimento dos grandes centros urbanos a partir das grandes feiras. Ambos os fatores aliados ao incremento da estrutura dos portos no tecido urbano ao longo do tempo, permitem compreender como se inserem os espaços portuários no contexto urbano, e qual a relação se estabelece entre eles. Para o presente trabalho, o processo de evolução da relação porto-cidade na história foi interpretado com base nos estudos de Monié (2011), Monié e Vasconcelos (2012), Monié e Vidal (2006) e Hoyle (1989).

Em termos de conceitualização da atividade avaliada, o porto trata-se de uma inserção da cadeia global de mercados em um espaço composto por 
relações regionais e locais, o espaço urbano. Esta trajetória pode ser analisada em três níveis (MONIÉ E VASCONCELOS, 2012):

- Global: através da globalização;

- Meso-econômico: no âmbito dos sistemas regionais que capturam os volumes crescentes de fluxos e das atividades de transformação; e

- Local: sobre o território da cidade portuária.

Relativos às diferentes escalas de análise, ainda é necessária a apreensão de alguns fatores específicos, os quais incidem diretamente na configuração espacial e da relação estabelecida entre as atividades portuárias e a dinâmica das cidades. Para a interpretação dos impactos na morfologia dos espaços de interface entre o porto e a cidade, é necessário considerar a evolução tecnológica; o desenvolvimento logístico; os atores portuários; as transformações no sistema marítimo internacional; a conjuntura global, assim como as dinâmicas globais enquanto fenômenos relevantes (MONIÉ; VASCONCELOS, 2012). Destaca-se que nem sempre tais fatores estão diretamente atrelados ao território sobre o qual incidem, sendo seu surgimento associado às dinâmicas globais de transporte, tecnologia, economia, entre outros. Dessa forma, relativo à escala local, a qual a cidade se relaciona diretamente, destaca-se, junto a estes fatores, as especificidades de cada cidade portuária (MONIÉ; VASCONCELOS, 2012).

Neste sentido, contextualizar a dinâmica de conformação urbana das cidades portuárias brasileiras é relevante quando se quer aprofundar a avaliação estratégica destes portos. Diferentemente dos centros europeus que se desenvolveram a partir de trocas comerciais em um vetor de entrada de novas matérias primas, com o desenvolvimento de funções manufatureiras, e financeiras em grande escala, as cidades portuárias brasileiras se configuraram a partir da dinâmica da colonização, no vetor contrário. Tem-se que "Os primeiros portos brasileiros funcionaram, assim, como portas de entrada dos colonizadores, de milhões de escravos, de bens manufaturados europeus, e como pontos de saída das riquezas do país" (MONIÉ apud. MONIÉ; VASCONCELOS, 2012, p.11).

Primeiramente, as cidades portuárias brasileiras se configuraram a partir do estabelecimento dos entrepostos comerciais, desenvolvendo funções auxiliares ao porto, enquanto centros administrativos. Monié e Vasconcelos (2012) ainda indicam a fixação de trabalhadores portuários e das atividades de apoio nas proximidades do Porto, nesta época, em virtude da precariedade da oferta de transportes públicos. Contudo, destaca-se que as áreas portuárias eram associadas à entrada de epidemias, sendo áreas evitadas para a fixação e residência pelas camadas sociais mais abastadas (HONORATO, 2008).

No Brasil, foi principalmente a partir da chegada da família real e da abertura dos portos às nações amigas, que houve um maior foco nos investimentos e intervenções em melhorias urbanas. Este período foi caracterizado pelas renovações urbanas nas principais cidades brasileiras, alavancadas pelo movimento higienista, o qual estabeleceu diretrizes para 0 desenvolvimento urbano que afastavam as cidades das áreas portuárias, em virtude do foco na salubridade dos espaços, e garantia da saúde pública através do planejamento urbano (COSTA, 2013).

A influência das novas dinâmicas econômicas, que surgem com 0 capitalismo industrial entre o século $X I X$ e $X X$, e se reforçam com a reestruturação econômica mundial neoliberal, no final do século XX, gerou um 
processo de diferenciação entre a função da zona portuária e do núcleo geracional das dinâmicas socioeconômicas do meio urbano, em escala mundial. As novas adaptações exigidas por tais mudanças, nas estruturas dos portos e infraestruturas do entorno, se tornaram incompatíveis com as funções e as formas urbanas por eles geradas no período das grandes navegações. Segundo Monié (2011), neste período "as infraestruturas evoluíam segundo uma lógica distinta da lógica da cidade" (MONIÉ, 2011, não paginado).

Principalmente a partir do aumento do transporte por contêineres em escala mundial, as estruturas necessárias aos portos, morfologicamente, se distinguiram da malha urbana de forma drástica. A partir deste momento histórico, os portos do hemisfério norte diferenciam-se dos brasileiros no tocante às funções do porto em relação ao espaço da cidade. Enquanto em países europeus, a tendência foi de recuperação da coesão entre o espaço até então ocupado pelos portos e o tecido urbano, no Brasil, a estrutura portuária e a urbana ganharam autonomia em suas relações, muitas vezes traduzida na distância física de suas estruturas, devido ao aumento da escala de produção e ao fortalecimento da conteinerização em nível internacional (ZANETTI, 2005). Segundo Monié e Vidal (2006),

\begin{abstract}
"Nesses sistemas circulatórios os portos também apresentaram uma evolução radical pela perda, parcial ou total, de suas funções comerciais tradicionais que se traduziram, por exemplo, pela degradação das áreas portuárias, cuja representação é cada vez mais negativa na sociedade devido tanto à sua associação sistemática aos problemas de insegurança, prostituição, engarrafamentos ou poluição ambiental quanto a estigmas e preconceitos."(MONIÉ; VIDAL, 2006, p.980).
\end{abstract}

Contudo, a mudança macroeconômica alavancou, no âmbito do planejamento urbano, discussões e implantações de planos estratégicos, voltados às operações econômicas que definem áreas de interesse de mercado na cidade, e que possibilitaram reestruturações territoriais com foco em investimentos de capital privado e atração de investimentos. A inserção das cidades em um mercado competitivo direcionou a gestão urbana às áreas estratégicas locais, a exemplo das áreas de orla, valorizadas pelas suas qualidades paisagísticas e, muitas vezes, de caráter central e histórico. Hoyle (1989) indica a reaproximação do espaço entre a cidade e o porto a partir dos anos 1970, nos países europeus, não mais pelas trocas comerciais realizadas por ele, mas pelas iniciativas de requalificação urbana das áreas portuárias esvaziadas e em condições de degradação (HOYLE, 1989). No Brasil, esse processo teve início, principalmente, a partir do ano 2000, com o projeto Estação Docas em Belém.

Segundo Del Rio (2016), o processo de revitalização de áreas portuárias "bem conduzido e com um correto faseamento, leva à maximização dos investimentos e ao sucesso nos campos econômico, cultural, habitacional, turístico, recreacional, entre tantos outros que se complementam." (DEL RIO, 2016, p. 01). Dessa forma, torna-se de vital importância na evolução da relação porto-cidade, a apreensão dos fatores principais no processo de consolidação 
de revitalizações portuárias no Brasil e no mundo, também no que se refere àqueles que configuram fraquezas, ou conferem sucesso às intervenções.

\subsection{Aspectos principais de avaliação no processo de elaboração e consolidação de projetos de revitalização portuária}

Haja vista o processo de articulação entre o espaço urbano e portuário evidenciado pela investigação da evolução da relação porto-cidade, as revitalizações portuárias passaram a se consolidar em todo mundo como contrapartida das condições de degradação das áreas centrais em que se localizam as estruturas portuárias do século XIX. Estas intervenções urbanas têm como característica o envolvimento de diversos atores na sua consolidação, os quais têm envolvimento desde o processo de elaboração do projeto, até à gestão do empreendimento realizado, com destaque para o papel do poder público na continuidade das estratégias de gestão e planejamento. Segundo Del Rio (2016) é a necessária consideração de diversos fatores para a realização e sucesso de tais projetos, como a condição espacial do local de implantação, as condições do mercado imobiliário da área, e as possibilidades de fontes de investimentos para a sua execução.

Em virtude da abrangência dos fatores envolvidos em sua implantação, as revitalizações portuárias podem ser caracterizadas como parte dos Grandes Projetos Urbanos (GPU) ou megaprojetos (LUNGO; SMOLKA, 2002, não paginado). Estas intervenções se multiplicaram a partir da ascensão do neoliberalismo e estabelecimento dos mercados globais competitivos, pois, segundo Li et. al. (2018) vem se tornando um fator chave para as estratégias de desenvolvimento econômico, social e urbano das cidades no contexto atual. Os GPUs se caracterizam por serem,
“(...) no sólo las grandes obras emblemáticas, sino también grandes operaciones urbanas que asumen, en muchos casos, la forma de programas de intervención a través de un conjunto de acciones urbanas de nivel intermedio que por su integración tienen un profundo impacto en el desarrollo de una ciudad." (LUNGO, 2005, não paginado)

Em uma análise dos estudos realizados acerca da avaliação dos GPUs, estes projetos devem ser avaliados, enquanto tais, quando compreenderem as seguintes características (ZACHETI; SOMEKH, 2014, p.11):

- "Têm perímetro definido de área urbana suficientemente grande";

- "São áreas com estoque imobiliário "obsoleto" e espaço público degradado";

- "Têm um projeto com gênese identificável";

- "São implantados no longo prazo";

- "Têm com objetivo principal a valorização relativa da área do projeto";

- "Estão associados a objetivos de aumentar da oferta imobiliária no mercado (estoque existente e/ou novos imóveis) e/ou aumento do emprego e da renda na área do projeto";

- "Usam estratégia adaptativa de implantação";

- "Requerem alto valor do investimento público e/ou privado";

- "Geram muitas externalidades na cidade"; 
- "Têm gestão específica (pública, privada ou pública/privada) subordinada a instrumentos normativos legais específicos".

Tais intervenções têm impacto relevante na configuração do espaço urbano e de seus entornos, bem como nas dinâmicas econômicas e sociais dessas áreas, e por isso, se configuram em elementos transformadores da relação porto-cidade dos municípios em que se encontram. Portanto, a partir do entendimento das revitalizações portuárias enquanto GPUs, parte-se para a compreensão dos principais aspectos considerados no seu processo de consolidação.

Uma vez indicado o espectro de abrangência dos GPUs, é possível agrupar as suas características em três grandes grupos, as características relacionadas ao espaço, as características relacionadas ao mercado e investimentos, e as características relacionadas à gestão do projeto. Tais grupos são indicados por Li et. al. (2018), em seu estudo sobre as características de gerenciamento de megaprojetos, enquanto as perspectivas do Sistema Socioeconômico; Sistema de Engenharia e Gerenciamento de Projetos, de Organizações e Governança.

A primeira perspectiva se refere a um sistema que engloba fatores estruturais amplos e se relaciona com o contexto histórico, as instituições, e os valores políticos vigentes, além dos processos de globalização e urbanização. A segunda perspectiva está relacionada às iniciativas de melhorias em design e gestão de projetos de engenharia, articulando os campos de conhecimento de infraestruturas, construções em larga escala, megaeventos e desenvolvimento urbano. Já a terceira perspectiva apontada pelos autores estudados, se refere às organizações dos GPUs e seus aspectos de governança, relacionando campos como a formação de redes e de liderança. Os aspectos citados indicados pela bibliografia estão elencados na Tabela 1.

\section{Tabela 1 - Caracterização das revitalizações portuárias}

\begin{tabular}{|c|c|c|c|}
\hline Perspectivas & Socioeconômica & $\begin{array}{c}\text { Engenharia e } \\
\text { Gerenciamento de } \\
\text { Projetos }\end{array}$ & $\begin{array}{c}\text { Organizações e } \\
\text { Governança }\end{array}$ \\
\hline \multirow{4}{*}{$\begin{array}{l}\text { Aspectos de } \\
\text { análise }\end{array}$} & $\begin{array}{c}\text { Efeitos } \\
\text { institucionais }\end{array}$ & $\begin{array}{c}\text { Projetos e sistemas } \\
\text { de engenharia }\end{array}$ & $\begin{array}{l}\text { Constituição de } \\
\text { redes }\end{array}$ \\
\hline & $\begin{array}{l}\text { Políticas } \\
\text { Públicas }\end{array}$ & $\begin{array}{l}\text { Otimização de } \\
\text { planejamento }\end{array}$ & $\begin{array}{l}\text { Aspectos de } \\
\text { governança }\end{array}$ \\
\hline & $\begin{array}{l}\text { Pesquisa } \\
\text { estratégica }\end{array}$ & $\begin{array}{c}\text { Análise de custo } \\
\text { benefício }\end{array}$ & $\begin{array}{l}\text { Aspectos de } \\
\text { liderança }\end{array}$ \\
\hline & $\begin{array}{l}\text { Análise de } \\
\text { decisão }\end{array}$ & $\begin{array}{l}\text { Gerenciamento de } \\
\text { riscos }\end{array}$ & $\begin{array}{c}\text { Gerenciamento } \\
\text { de riscos }\end{array}$ \\
\hline
\end{tabular}

Fonte: Li et. al. (2018).

O Banco Mundial (2016) realizou uma pesquisa para a avaliação do desempenho de projetos de gestão urbana, que reforça a consideração das perspectivas já citadas por $\mathrm{Li}$ et. al. enquanto fatores relevantes. Ao avaliar o desempenho das intervenções urbanas, são indicados os fatores motivadores de sucessos e de insucessos reconhecidos pela instituição, os quais se tornam de primordial análise em uma etapa de tomada de decisão ex-ante. Para a pesquisa realizada pelo órgão, foram considerados os modelos institucionais; as políticas jurídicas, institucionais e regulatórias; e a inclusão social dos projetos 
VI CIDESPORT/2019

Congresso Internacional

de Desempenho Portuário

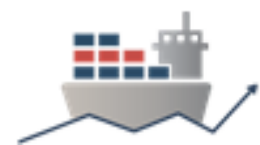

avaliados. Nesse sentido, os fatores de sucesso e de insucesso apontados pela pesquisa realizada pelo Banco Mundial (2016), estão elencados na Tabela 2.

Tabela 2 - Aspectos de sucesso e insucesso de Projetos de Gestão Urbana

Aspectos de sucesso

Aspectos de insucesso

Consideração das especificidades locais na elaboração dos projetos

Comprometimento político

Medidas de atendimento às demandas de populações vulneráveis

Modelos institucionais inflexíveis

Projetos de modelos não

adaptáveis a longo prazo

Avaliação dos impactos do projeto em desarticulação com sistema econômico, regulatório e institucional em que está inserido

\section{Fonte: Banco Mundial (2016)}

A análise do Banco Mundial (2016) adiciona à análise realizada por Li et. al. a importância dos atores envolvidos no processo, bem como as características das especificidades locais, colocadas por Monié e Vasconelos (2012) como essenciais ao entendimento da relação porto-cidade. Assim, como complementação a esta análise, Del Rio (2016) indica algumas características essenciais para a consolidação das revitalizações portuárias no contexto brasileiro. $\mathrm{O}$ autor coloca que,

"a colaboração entre o poder público (viabilizadores), o poder privado investidores) e as comunidades (moradores e usuários) garante a identificação de planos e programas que possam maximizar e compatibilizar os esforços e os investimentos, e nortear a implementação integrada de ações e projetos a curto, médio e longo prazos" (DEL RIO, 2016, p.02).

A fim de que se construa uma análise concisa da relação entre o espaço portuário e urbano, o autor também indica como necessária a consideração da conjuntura histórica, econômica global, os atores portuários envolvidos, e das particularidades locais, adicionando a estas, já citadas pelos demais autores pesquisados, características estéticas e relacionadas aos projetos das intervenções. Os aspectos aos quais o autor atribui o sucesso das revitalizações portuárias são resumidos em 5 :

“a) os processos estratégicos de planejamento, marketing, gestão e monitoramento, em perspectivas de longo prazo;

b) um mix estudado de ocupação da área, composto por diversos usos do solo, complementares e com a presença de "âncoras" sólidas;

c) respeito à memória coletiva, ao patrimônio e ao contexto preexistente (físico-espacial e socio-cultural);

d) atenção ao poder das imagens e da qualidade projetual;

e) processos consensuais e colaborativos entre os grupos 
VI CIDESPORT/2019

Congresso Internacional

de Desempenho Portuário

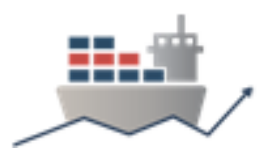

envolvidos (instâncias de governo, investidores, empresariado, usuários e comunidade em geral)" (DEL RIO, 2016, p.09).

Assim, uma vez pesquisados os principais aspectos para a avaliação e sucesso de revitalizações portuárias, enquanto GPUs são consideradas também as condições da relação entre o porto e a cidade que se estabelece a partir da sua consolidação. Dado o aporte teórico indicado é possível, então, caracterizar tais aspectos nas análises das experiências internacionais e do caso brasileiro.

\section{PROCEDIMENTOS METODOLÓGICOS}

Os procedimentos metodológicos do presente trabalho, visaram ao atendimento do seu objetivo geral que compreende a caracterização dos principais aspectos a serem avaliados para a tomada de decisão ex-ante de uma revitalização portuária, considerando seu sucesso e seus impactos na relação porto-cidade. Trata-se de uma pesquisa qualitativa, resultando em uma análise interpretativa dos dados através do método de triangulação teórica (DUARTE, 2009). Tal esforço demandou a busca pela relevância das revitalizações portuárias inseridas no processo de evolução da relação porto-cidade; da conexão entre as revitalizações portuárias e os GPUS; da definição dos GPUs; dos principais aspectos analisados nos estudos sobre GPUs; e então, da utilização de tais aspectos para a interpretação das experiências internacionais e brasileiras.

A fim de situar as revitalizações portuárias enquanto fenômenos partícipes do processo histórico de evolução da relação porto-cidade foi realizada uma revisão bibliográfica qualitativa. Foi realizada a análise da bibliografia dos instrumentos de planejamento portuário nacionais, os Planos Mestres Portuários, sendo encontrado o artigo de referência de Monié e Vasconcellos (2012). A partir desta referência, foram investigadas outras publicações acadêmicas do autor acerca do tema porto-cidade, bem como a investigação da bibliografia utilizada em seus artigos. Desta forma, foram definidas como referências bibliográficas a análise realizada os artigos Monié (2011), Monié e Vasconcelos (2012), Monié e Vidal (2006) e Hoyle (1989).

Para a caracterização dos GPUs, foi realizada uma revisão bibliográfica sistemática, sendo pesquisada a plataforma Scopus, com as palavras-chaves "mega-projects and investments" e "waterfront renewal financial", em que foram encontrados respectivamente 131 e 9 resultados. Na plataforma Lincoln Institute, por sua vez, foram pesquisadas as palavras chaves "urban projects", "port urban revitalization" e "urban revitalization", sendo encontrados, respectivamente, a seguinte quantidade de resultados: 1337, 2978, 2874. De forma complementar à revisão sistemática, foram pesquisadas as referências utilizadas pelos artigos selecionados dentre os resultados apresentados nas plataformas consultadas, pelo método qualitativo. Estas referências acadêmicas foram utilizadas em virtude da sua citação em temáticas específicas de interesse. Dados os resultados elencados, foram selecionados as referências pertinentes ao objetivo do trabalho, a saber as caracterizações propostas por Lungo e Smolka (2002) e Zancheti e Somekh (2014).

Subsequentemente, foram realizados os mesmos procedimentos de pesquisa qualitativa das referências bibliográficas já selecionadas, agora voltada à caracterização dos principais aspectos analisados no processo de 
consolidação, sucesso e insucesso dos GPUs, e de revitalizações portuárias. As referências elencadas para os aspectos analisados nos GPUs pela bibliografia foram os estudos de Del Rio (2016), Li et. al. (2018) e a publicação do Banco Mundial (2016).

Uma vez determinada a bibliografia utilizada para a caracterização dos GPUs, tais referências serviram como base para a realização da análise das experiências internacionais e do caso brasileiro. Para a experiência internacional, foram realizadas pesquisas na plataforma Google Acadêmico com as palavras chaves "Bilbao urban redevelopment"; "puerto de Barcelona revitalizacion"; "puerto de Barcelona remodelacion"; "urban development Marseilles port"; "Cité de la Méditerranée waterfront marseille"; "kop van zuid Rotterdam regeneration"; "port development Barcelona"; "port development project Rotterdam"; "proyecto urbano puerto Barcelona" e "Barcelona port spaces development", sendo encontrados um total de 3.650; 13.500; 10.100; 4.300; $21.400 ; \quad 235 ; \quad 512 ; 165.000 ; 77.400 ; 64.600$ e 49.600 resultados, respectivamente. A partir da seleção dos títulos mais adequados à presente pesquisa, foi feita a leitura da introdução dos artigos acadêmicos e a seleção de 9 deles como base de informações acerca das revitalizações portuárias. Nesse sentido, os artigos de Ponzini (2010); Gómez (2015); Magrinyà e Maza (2012); Sutton (2015); Urbed e Van Hoeck (2007); Magrinyà e Maza (2005); Giovinazzi e Moretti (2010); Bergsli (2008) e Daamen e Vries (2013) compuseram a base para o enquadramento das experiências de revitalizações portuárias internacionais enquanto GPUs. Além destes, também foi utilizado como referência, o guia de boas práticas da Rede Internacional de Cidades Portuárias (AIVP), intitulado "Plan the city with the port".

Já para a seleção das experiências nacionais foram realizadas pesquisas nos documentos de planejamento portuário brasileiro, os Planos Mestres Portuários. Com base nestes documentos, foram eleitas para pesquisa as revitalizações urbanas que se enquadram nas características dos GPUs propostas por Zancheti e Somekh (2014). De forma complementar, foram buscadas informações em fontes pontuais como sites governamentais, para instrumentos de legislação e planejamento, e de artigos acadêmicos específicos sobre as revitalizações já selecionadas, nas plataformas Google Acadêmico e Scopus, utilizando como palavras-chave "Revitalizações Portuárias" os nomes dos projetos de revitalizações, a saber: Porto Maravilha, Estação Docas, Belém Porto Futuro e Porto Novo. Dentre os resultados obtidos, a seleção foi feita pela leitura dos títulos e seções de introdução, sendo considerados como fontes de dados os artigos de Tavares e Kiyotani (2013); Werneck, Novaes e Júnior (2018); Arruda (2003); Mendonça (2014); e Ponte (2007). Além dos documentos técnicos das parcerias público privadas dos projetos pesquisados, e instrumentos de planejamento governamentais.

Finalmente, para a análise qualitativa tanto das experiências internacionais, quanto nacionais, a partir dos aspectos apontados pela bibliografia, foi realizado o método de triangulação teórica, segundo as definições de Duarte (2009). A partir dos aspectos definidos pelas três referências bibliográficas, os estudos de Del Rio (2016), Li et. al. (2018) e do Banco Mundial (2016), evidenciaram-se os aspectos a serem combinados de forma útil à interpretação do conjunto de informações e dados coletados das revitalizações portuárias internacionais e nacionais selecionadas. 


\section{RESULTADOS}

Dadas as três referências bibliográficas para os principais aspectos analisados em GPUs, no que concerne aos estudos já realizados, bem como à consideração do seu sucesso em insucesso, foi possível estabelecer a relação entre tais aspectos e as revitalizações urbanas pesquisadas. Na triangulação teórica proposta foram combinados os aspectos colocados pelos autores estudados, partir de sua utilidade para a interpretação das experiências internacionais e nacionais, considerando as revitalizações portuárias inseridas na evolução da relação porto-cidade.

Os aspectos avaliados, indicados pela bibliografia, foram agrupados em três grandes perspectivas, a exemplo do estudo de Li et. al.: econômica, urbanística e de gerenciamento de projeto, institucional e de governança. Cada uma destas perspectivas engloba aspectos específicos, que resultaram também da combinação dos aspectos de análise indicados pela bibliografia e sua adequação ao objetivo do trabalho. É relevante apontar, que a perspectiva urbanística e de gerenciamento de projeto engloba um aspecto específico a mais do que as demais perspectivas, em virtude da relevância da constituição morfológica da cidade na conceituação bibliográfica da relação porto-cidade, como indicado na primeira seção 2.1 do trabalho. Assim, os aspectos específicos definidos foram:

1. Flexibilização do sistema regulatório: sua avaliação se deu a partir da existência, durante o processo de consolidação das revitalizações portuárias analisadas, de incentivos fiscais para a sua implementação, ou pela flexibilização de aspectos jurídicos e regulatórios a exemplo de alterações no zoneamento urbano;

2. Consideração das especificidades locais: se refere às diretrizes ou medidas de valorização das atividades econômicas tradicionais e dos bens históricos culturais como fatores de dinamização da economia;

3. Parceria público privada: indica a existência de investimentos financeiros tanto de caráter público quanto privado, o que configura um fator de análise importante, segundo a bibliografia;

4. Alteração na infraestrutura urbana: se refere à verificação de investimentos em melhorias de infraestrutura urbana, como sistema viário e sistema de drenagem, não somente na área direta de intervenção da revitalização, configurando intervenções também utilizadas pela população da cidade como um todo;

5. Gestão estratégica de projeto: é a análise da existência de medidas estratégicas para o projeto como ações de marketing, além do planejamento e monitoramento do projeto em longo prazo;

6. Qualificação de uso e ocupação: aponta a existência de diretrizes de ocupação voltadas à diversidade de usos no projeto de revitalização portuária, tais como turismo, habitação e uso comercial, assim como a consideração de aspectos estéticos na área de intervenção;

7. Integração da área revitalizada com a malha urbana: avalia a integração da área revitalizada com a malha urbana, por meio da permeabilidade visual e integração da orla e acessibilidade da área por meio de transporte público;

8. Participação da sociedade civil: se refere à existência de participação da sociedade civil no processo de consolidação do projeto de revitalização 
portuária por meio de consultas públicas e alternativas de acesso à informação, como websites ou aplicativos;

9. Existência de órgão específico de gestão: se refere à constatação de órgãos de gestão específicos voltados área revitalizada e sua interação com a cidade, com atuação durante o processo de implantação do projeto e posterior funcionamento; e

10. Processo colaborativos de deliberação: está relacionado à existência de espaços deliberativos com o envolvimento de diversos atores interessados, a exemplo da realização de fóruns e audiências públicas.

\subsection{Análise da experiência internacional}

Em sequência, foram analisados os empreendimentos de revitalização de áreas portuárias no âmbito internacional. Pioneiros nesse campo, estas intervenções se apresentaram como soluções para as renovações econômicas do fim do século $\mathrm{XX}$, guiados por estratégias que contemplam a projeção das cidades no mercado mundial, como citado anteriormente. A escolha das cidades contempladas neste artigo baseou-se na relevância no cenário mundial de grandes projetos e nas características de revitalizações portuárias apresentadas anteriormente, com base em Zacheti e Somekh (2014).

Tabela 3 - Caracterização das revitalizações portuárias internacionais

\begin{tabular}{|c|c|c|c|c|}
\hline & Marselha & Barcelona & Roterdã & Bilbao \\
\hline \multicolumn{5}{|c|}{ ASPECTOS ECONÔMICOS, JURÍDICOS E REGULATÓRIOS } \\
\hline $\begin{array}{l}\text { FLEXIBILIZAÇÃO DO SISTEMA } \\
\text { REGULATÓRIO }\end{array}$ & SIM & SIM & SIM & SIM \\
\hline $\begin{array}{l}\text { CONSIDERAÇÃO DAS } \\
\text { ESPECIFICIDADES LOCAIS }\end{array}$ & SIM & SIM & SIM & NÃO \\
\hline PARCERIA PÚBLICO PRIVADA & SIM & SIM & SIM & SIM \\
\hline \multicolumn{5}{|c|}{ ASPECTOS URBANÍSTICOS EGERENCIAMENTO DE PROJETO } \\
\hline $\begin{array}{l}\text { ALTERAÇÃO NA INFRAESTRUTURA } \\
\text { URBANA }\end{array}$ & SIM & SIM & SIM & SIM \\
\hline $\begin{array}{l}\text { GESTÃO ESTRATÉGICA DE } \\
\text { PROJETO }\end{array}$ & SIM & SIM & SIM & SIM \\
\hline $\begin{array}{l}\text { QUALIFICAÇÃO DE USO E } \\
\text { OCUPAÇÃO }\end{array}$ & SIM & SIM & SIM & SIM \\
\hline $\begin{array}{l}\text { INTEGRAÇÃO DA ÁREA } \\
\text { REVITALIZADA COM A MALHA } \\
\text { URBANA }\end{array}$ & SIM & SIM & SIM & SIM \\
\hline \multicolumn{5}{|c|}{ ASPECTOS INSTITUCIONAIS EDE GOVERNANÇA } \\
\hline $\begin{array}{l}\text { PARTICIPAÇÃO DA SOCIEDADE } \\
\text { CIVIL }\end{array}$ & IM & SIM & SIM & NÃO \\
\hline $\begin{array}{l}\text { EXISTÊNCIA DE ÓRGÃO } \\
\text { ESPECÍFICO DE GESTÃO }\end{array}$ & SIM & SIM & SIM & SIM \\
\hline $\begin{array}{l}\text { PROCESSOS COLABORATIVOS DE } \\
\text { DELIBERAÇÃO }\end{array}$ & SIM & SIM & SIM & SIM \\
\hline
\end{tabular}

Fonte: Anexo I

Em uma avaliação geral, pode-se observar a adequação dos projetos aos aspectos principais de análise, de acordo com a bibliografia de referência, para 
a maior parte dos casos. A fim de qualificar a análise, buscou-se destacar, a seguir, as características de maior relevância de cada projeto.

Primeiramente, em Bilbao, na Espanha, com a formação da instituição Bilbao Ría 2000, formada exclusivamente por representantes do governo local, regional e central, estabeleceu-se um órgão capaz de gerar um impulso fundamental no novo modelo de política urbana, baseado na gestão econômica estratégica. Apesar de ser formalmente definida como uma empresa privada, a Ría 2000 atua como uma parceria entre órgãos públicos que discutem as decisões de planejamento da revitalização coletivamente, com objetivo de planejar instalações e implementar operações, no que diz respeito à disposição e uso de terras e outras propriedades, às prioridades de intervenção, às características construtivas e à gestão de recursos públicos para 0 redesenvolvimento da área urbana a receber as intervenções (AIVP, 2015; PONZINI, 2010).

Em relação aos aspectos econômicos, como um órgão específico de gestão, a Bilbao Ría 2000 foi responsável por investir um montante inicial integralmente público na compra de terrenos pelos seus acionistas, que, amparados pelo novo zoneamento do uso do solo pelas autoridades públicas, puderam revendê-los com finalidades de uso voltadas principalmente para a habitação. Este processo rendeu a primeira receita da instituição, que então passou a investir em projetos efetivos de revitalização, dentre os quais figuram o Museu Guggenheim, do arquiteto Frank Gehry, responsável por gerar recursos em novos setores econômicos e considerado um expoente da cidade, em nível internacional (AIVP, 2015); assim como o novo aeroporto e o novo sistema de metrô, também desenhados por arquitetos renomados.

$\mathrm{Na}$ ocasião da elaboração do projeto, houve, ainda, a influência de um segundo órgão, denominado Bilbao Metropoli 30, que desempenhou um importante papel na consolidação do projeto, reunindo os municípios da região metropolitana de Bilbao, o governo basco, o porto e investidores privados, voltados a difundir a imagem da região através de estratégias de marketing urbano. Exemplos, tanto dos aspectos institucionais e de governança, quanto de gestão estratégica do projeto.

No tocante aos aspectos urbanísticos, destaca-se o caso de Barcelona como um exemplo de remodelação urbanística com qualificação de uso e ocupação e de investimentos na infraestrutura urbana. A revitalização da zona portuária em Barcelona surgiu no contexto da preparação da cidade para sediar os Jogos Olímpicos de 1992. A expectativa de realização do grande evento gerou a atração de investimentos na área e impulsionou o processo de renovação urbanística do Port Vell em Barcelona. Com o objetivo de urbanizar e gerir toda área ocupada pelo Port Vell, criou-se, em 1988, a Gerencia Urbanística Port 2000, que consistia em órgão de gestão de natureza público-privada (SUTTON, 2015). Desta forma, foram planejados quatro grandes projetos: o Moll de la Fusta (1981-1987), o Moll de la Barceloneta (1988-1993), Moll d'Espanya/Maremagnum (1994-1996) e o Moll de Barcelona (1998-2000) (MAGRINYÀ; MAZA, 2005). Além dos quatros projetos citados, grandes obras de infraestrutura foram implementadas, a exemplo das mudanças na mobilidade, a partir da separação do fluxo de tráfego portuário e urbano, por meio da reorganização dos acessos rodoviários e ferroviários e a expansão do anel viário (AIVP, 2015). 
A partir da implementação do Moll de la Fusta na região do Port Vell, sob a responsabilidade do arquiteto Manuel de Solà-Morales, iniciou-se a retomada da relação da cidade com a frente marítima e a construção de uma remodelação urbana baseada na diversidade de usos. Dentre os principais aspectos dos projetos subsequentes pode-se citar a demolição de antigos armazéns do porto para a concepção de novos passeios para pedestres e ciclistas, qualificados com diferentes tipos de pavimentação e cuidados paisagísticos. Estas vias peatonais inauguradas foram responsáveis por estabelecer novas relações visuais entre $o$ porto e a cidade. Outro importante elemento do projeto foi a construção da ponte Rambla del Mar, no Moll d'Espanya, que instaurou uma conexão direta entre a zona portuária e as demais ramblas, conhecidas como calçadões, presentes ao longo do centro histórico de Barcelona (MAGRINYÀ; MAZA, 2012). Ainda no Moll d'Espanya, reúnem-se grandes atrativos turísticos, como o shopping center Maremagnum, um aquário e um cinema. Ao longo do Port Vell nota-se também a presença de edifícios históricos, como o Palácio do Mar, que abriga o Museu de História da Catalunha, restaurantes e escritórios. Por fim, o Moll de Barcelona, inaugurado no ano de 2000, representa uma outra esfera na centralidade do Port Vell, com a instalação do parque empresarial World Trade Center e de hotéis.

Assim como em Barcelona, Marselha também ganha destaque no âmbito dos aspectos urbanísticos. O projeto Euromediterranée, gerido por um conselho de administração composto por representantes do Estado francês e autoridades locais, foi estabelecido sobre estratégias comuns acordadas entre o Porto Autônomo e a administração da cidade, com consultas eventuais à comunidade local. Esta intervenção é tida como o maior empreendimento em renovação urbana do continente europeu, e é dividido em uma série de iniciativas públicas e privadas, distribuídas em regiões que permeiam a orla e adentram a malha urbana, com papéis específicos econômicos, voltados a fins de serviços, de escritórios. Além destes, destacam-se as áreas de parques e complexos culturais e turísticos, que renderam ao município a nomeação de Capital Europeia da Cultura, em 2013 (GIOVINAZZI; MORETTI, 2010). O objetivo é implementar um programa multifuncional focado principalmente no setor terciário, assim como em educação, cultura, turismo e recreação, a fim de criar um lugar com vitalidade e que possa ser apropriado tanto pelo povo de Marselha quanto pelos moradores dos arredores do centro metropolitano (BERGSLI, 2008).

Dentre as intervenções, salienta-se o Terrasses du Port, edifício que serve de terminal de cruzeiros e tem funções de comércio e serviços, como cafés e lojas e restaurantes, e o Silo d'Arenc, obra de restauração de uma importante estrutura portuária antiga, tida como patrimônio cultural, onde foram alocados escritórios e um espaço para apresentações. Ambos estão projetados de forma a não terem contato direto com as atividades portuárias, respeitando-se as legislações de segurança (DAAMEN; VRIES, 2013). Além destes, também se destaca a demolição de um viaduto que segregava o cais de Joliette da malha urbana, que foi substituído por um túnel subterrâneo e possibilitou assim a criação de um boulevard, com espaço para pedestres e ciclistas e que conecta algumas das novas das instalações previstas no projeto e tem seu uso revertido não só para usuários da área, e compreende uma melhoria para a mobilidade urbana da cidade de forma geral (AIVP, 2015).

No caso da revitalização portuária de Roterdã, o projeto conhecido como Kop van Zuid destaca-se no âmbito da participação popular, por meio da 
organização de grupos de moradores que reivindicaram benefícios em prol das comunidades dos bairros do entorno da zona portuária. Estes bairros adjacentes à área eram marcados pelo desemprego, criminalidade e baixo nível de escolaridade dos habitantes. Desta forma, o envolvimento da sociedade civil no projeto foi determinante para a prefeitura criar o programa social denominado "Benefício Mútuo", o qual visava duas metas principais: a recomendação para a contratação de residentes locais nas obras de desenvolvimento e manutenção do projeto e o incentivo à criação de empresas de pequeno e médio porte nestes bairros contíguos. Outro ponto relacionado aos aspectos institucionais e de governança no desenvolvimento do Kop van Zuid foi a instalação de centros de informação destinados tanto à população local quanto para investidores e turistas (URBED;VAN HOECKE, 2007).

\subsection{Caracterização das revitalizações portuárias no Brasil}

Para a interpretação das particularidades locais das revitalizações portuárias, foram analisadas as iniciativas mais expressivas em território nacional que se adequam na bibliografia apresentada, a saber: a revitalização Porto Maravilha no município do Rio de Janeiro (2015); as revitalizações Estação Docas (2000) e Belém Porto Futuro (em andamento), ambas em Belém e a revitalização Porto Novo (em andamento), em Recife. Em consonância com a metodologia realizada para a análise dos principais aspectos das revitalizações portuárias internacionais, a Tabela 4 caracteriza os grandes projetos urbanos portuários em território nacional.

Tabela 4 - Caracterização das revitalizações portuárias em território brasileiro

\begin{tabular}{|c|c|c|c|c|}
\hline & $\begin{array}{c}\text { PORTO } \\
\text { MARAVILHA } \\
\text { Rio de Janeiro }\end{array}$ & $\begin{array}{l}\text { ESTAÇÃO } \\
\text { DOCAS } \\
\text { Belém }\end{array}$ & $\begin{array}{c}\text { BELÉM PORTO } \\
\text { FUTURO } \\
\text { Belém }\end{array}$ & $\begin{array}{c}\text { PORTO } \\
\text { NOVO } \\
\text { Recife }\end{array}$ \\
\hline \multicolumn{5}{|c|}{ ASPECTOS ECONÔMICOS, JURÍDICOS E REGULATÓRIOS } \\
\hline $\begin{array}{l}\text { FLEXIBILIZAÇÃO DO SISTEMA } \\
\text { REGULATÓRIO }\end{array}$ & SIM & NÃO & NÃO & NÃO \\
\hline $\begin{array}{l}\text { CONSIDERAÇÃO DAS } \\
\text { ESPECIFICIDADES LOCAIS }\end{array}$ & NÃO & SIM & NÃO & NÃO \\
\hline PARCERIA PÚBLICO PRIVADA & SIM & SIM & SIM & SIM \\
\hline \multicolumn{5}{|c|}{ ASPECTOS URBANÍSTICOS E GERENCIAMENTO DE PROJETO } \\
\hline $\begin{array}{l}\text { ALTERAÇÃO NA } \\
\text { INFRAESTRUTURA URBANA }\end{array}$ & SIM & NÃO & NÃO & SIM \\
\hline $\begin{array}{l}\text { GESTÃO ESTRATÉGICA DE } \\
\text { PROJETO }\end{array}$ & SIM & SIM & NÃO & NÃO \\
\hline $\begin{array}{l}\text { QUALIFICAÇÃO DE USO E } \\
\text { OCUPAÇÃO }\end{array}$ & SIM & SIM & SIM & SIM \\
\hline $\begin{array}{l}\text { INTEGRAÇÃO DA ÁREA } \\
\text { REVITALIZADA COM A MALHA } \\
\text { URBANA }\end{array}$ & SIM & SIM & SIM & SIM \\
\hline \multicolumn{5}{|c|}{ ASPECTOS INSTITUCIONAIS EDE GOVERNANÇA } \\
\hline $\begin{array}{l}\text { PARTICIPAÇÃO DA SOCIEDADE } \\
\text { CIVIL }\end{array}$ & NÃO & SIM & NÃO & NÃO \\
\hline $\begin{array}{l}\text { EXISTÊNCIA DE ÓRGÃO } \\
\text { ESPECÍFICO DE GESTÃO }\end{array}$ & SIM & SIM & NÃO & NÃO \\
\hline $\begin{array}{l}\text { PROCESSOS COLABORATIVOS } \\
\text { DE DELIBERAÇÃO }\end{array}$ & SIM & SIM & SIM & SIM \\
\hline
\end{tabular}

Fonte: Anexo II

Salienta-se que das revitalizações supracitadas todas, exceto a Estação Docas finalizada no ano 2000 , possuem relação direta com a realização dos 
eventos multinacionais no Brasil, sendo eles a Copa do Mundo 2014 e as Olimpíadas 2016 (RIO DE JANEIRO, c201-; MENDONÇA, 2014). Esta característica evidencia a ligação entre as revitalizações portuárias e a tendência do planejamento urbano estratégico em território brasileiro, como indicado na sua relação com a evolução da relação porto-cidade.

É relevante destacar, também, que todas as quatro revitalizações em questão possuem como forma de financiamento as Parcerias Público Privadas (PPPs). As PPPs no Brasil foram legitimadas através do Estatuto da Cidade, estipulado pela Lei $n^{\circ} 10.257$ de 2001. O Estatuto da Cidade institui instrumentos de planejamento e financiamento urbano os quais viabilizam as PPPs, a exemplo da Outorga Onerosa do Direito de Construir (OODC) e da Operação Urbana Consorciada (OUC). A OODC é um instrumento que consiste na cobrança de uma contrapartida pelo ente privado para que ele possua o direito de construir acima do coeficiente de aproveitamento básico adotado por cada município para cada terreno. As OUCs, por sua vez, têm como objetivo promover transformações urbanísticas, estruturais, melhorias sociais e a valorização ambiental através de recursos obtidos por meio das contrapartidas dadas pela iniciativa privada. Como benefícios aos entes privados, tem-se a possibilidade do aumento dos índices urbanísticos no perímetro da OUC. Através deste instrumento, o poder público assume a iniciativa do processo de produção do espaço urbano e participa da valorização imobiliária provocada, visando tanto objetivos sociais quando o aumento de oportunidades para atuação da iniciativa privada (BRASIL, 2001).

A revitalização Porto Maravilha, como nomeada a transformação da área portuária do município do Rio de Janeiro, foi financiada através da OUC de mesmo nome, promulgada pela Lei Complementar n. ${ }^{\circ}$ 101/2009 (RIO DE JANEIRO, 2009). A OUC contou com a venda de Certificados de Potencial Adicional de Construção (CEPACs) para a captação de recursos a serem aplicados nos investimentos públicos da revitalização. Os CEPACs são título vendidos em bolsas de valores, que dão aos compradores direitos adicionais de construção, tendo suas vendas intrinsecamente relacionadas ao preço dos imóveis do entorno e eventuais modificações na conjuntura econômica que afetem o mercado imobiliário. Desta forma, o recesso econômico vivenciado pelo Brasil da década de 2010, dentre outros fatores, trouxe como consequência uma menor arrecadação com a venda de CEPACS para OUC Porto Maravilha, não obtendo assim sucesso financeiro almejado (WERNECK; NOVAES; JÚNIOR, 2018; BRASIL, 2001).

A OUC proporcionou também uma alteração do zoneamento e uso do solo do entorno da antiga área portuária carioca, possibilitando assim, uma maior diversidade de usos. O estímulo aos usos de comércio e serviço, assim como os usos residenciais e institucionais também se fizeram presentes. Dos 77 empreendimentos privados licenciados até dezembro de 2018 da OUC, 57 possuíam uso comercial, enquanto 11 possuíam uso residencial ou misto (WERNECK; NOVAES; JÚNIOR, 2018).

Conforme analisado no procedimento metodológico, dentre as características que contribuem para o sucesso dos GPUs, tem-se a criação de órgão gestores específicos para eles. No caso da Estação das Docas, no município de Belém, para gestão do empreendimento foi criada a Organização Social Pará 2000, uma instituição caracterizada como pessoa jurídica de direito privado sem fins lucrativos, sendo subsidiada pelo governo estadual e composta 
pela Secretaria de Turismo e Cultura e por diversos segmentos da sociedade civil. Já a revitalização Porto Novo Recife, não apresenta um órgão especial para gestão do empreendimento, tampouco foram verificados espaços para a participação social. Ademais, apesar de haverem movimentos sociais ativos dentro do perímetro do GPU, o projeto do Porto Novo não apresenta a inclusão do componente da habitação de interesse social, ou medida semelhante de atendimento às populações vulneráveis do entorno, existindo assim, movimentos atuantes no sentido de resistência ao projeto (MENDONÇA, 2014).

Outra questão projetual que viabiliza uma melhor relação da interface porto-cidade é a criação de conexões claras entre a antiga área portuária e a malha urbana existente. $O$ projeto Belém Porto Futuro tem destaque neste aspecto, ao oportunizar, tanto uma maior permeabilidade visual com os corpos d'água, quanto a incorporação de uma antiga via portuária pelo projeto, a Rua Belém. Ademais, o projeto Belém Porto Futuro realiza uma ampliação da infraestrutura urbana ao projetar a construção de uma ponte sobre o canal da Av. Visconde de Souza Franco e a instalação de um Terminal Multiuso no entorno da área portuária, promovendo assim maior acessibilidade ao local (BRASIL, 2017).

\section{CONCLUSÕES}

Através da presente análise e avaliação das revitalizações portuárias segundo os aspectos principais estabelecidos, é possível concluir que, em âmbito nacional e internacional, são recorrentes a realização destes GPUs voltados ao turismo, consolidados e financiados por parcerias público-privadas, e que proporcionam uma maior integração da malha urbana para com a antiga área portuária. Ainda se destacam de forma geral nas revitalizações portuárias pesquisadas, dois aspectos de sucesso ainda não explorados, sendo a participação social no processo de consolidação dos projetos, que é ainda pouco verificada no mundo quanto no Brasil. Da mesma forma, a valorização das especificidades locais não é unanimidade, fator que seria de especial valor no contexto multicultural brasileiro, bem como de importantes bens históricos próximos às áreas portuárias.

Nota-se uma grande defasagem entre os projetos nacionais quando comparados aos internacionais, de forma que os estrangeiros cumprem com maior efetividade a existências dos aspectos avaliados nas suas respectivas revitalizações. Ressalta-se nos projetos internacionais como aspectos importantes, não encontrados de forma tão presente no contexto nacional, a flexibilização do sistema regulatório, bem como a alteração na infraestrutura urbana e gestão estratégica no projeto, tópicos avaliados como existente nos quatro projetos urbanos estudados do Brasil.

Dessa forma, os aspectos analisados para a avaliação das revitalizações portuárias, principalmente enquanto medidas de sucesso e insucesso, compreendem um insumo importante para futuros projetos acerca do processo de tomada de decisão ex-ante das revitalizações portuárias com dados empíricos, com a possibilidade da pesquisa de estudos de caso, bem com para a proposição de metodologias nesse sentido. A análise realizada ratifica a importância de valorização das áreas portuárias, considerando ainda a vasta existência de antigas áreas portuárias ociosas nos centros urbanos, a localização privilegiada destas áreas bem como do seu alto poder de impacto 
VI CIDESPORT/2019

Congresso Internacional

de Desempenho Portuário

nas cidades portuárias de forma abrangente, alertando para melhorias ainda a serem realizadas, principalmente no contexto nacional.

\section{REFERÊNCIAS}

BRASIL. Lei $n^{\circ} 10.257$, de 10 de julho de 2001. Regulamenta os arts. $182 \mathrm{e}$ 183 da Constituição Federal, estabelecendo diretrizes gerais da política urbana e dá outras providências. Brasil, 10 jul. 2001. Disponível em: www.planalto.gov.br/ccivil_03/leis/leis_2001//10257.htm. Acesso em: 03 jul. 2019.

COSTA, Maria Clélia Lustosa. Influência do discurso médico e do higienismo no ordenamento urbano. Revista da Associação Nacional de PósGraduação e Pesquisa em Geografia (ANPEGE), v. 9, n. 11, p. 63-73, jan./jun. 2013. Disponível em:

ojs.ufgd.edu.br/index.php/anpege/article/view/6492/3473. Acesso em: 12 jul. 2019.

DEL RIO, Vicente. Voltando às origens. A revitalização de áreas portuárias nos centros urbanos. Arquitextos, São Paulo, ano 02, n. 015.06, Vitruvius, ago. 2001. Disponível em:

http://www.vitruvius.com.br/revistas/read/arquitextos/02.015/859.

DUARTE, Teresa. A possibilidade da investigação a 3: reflexões sobre triangulação (metodológica). Cies E-working Papers, Lisboa, n. 60, p.2-24, 2009. Disponível em: $<$ https://repositorio.iscteiul.pt/bitstream/10071/1319/3/CIES-WP60\%20_Duarte.pdf>. Acesso em: 06 ago. 2019.

HONORATO, Cláudio de Paula. Valongo: o mercado de escravos do Rio de Janeiro, 1758 a 1831. 2008. 166p. Dissertação (Mestrado em História).

Programa de Pós-Graduação em História. Universidade Federal Fluminense.

Disponível em:http://www.historia.uff.br/stricto/teses/Dissert-

2008 HONORATO Claudio de Paula-S.pdf. Acesso em: 10 jul. 2019.

HOYLE, Brian Stewart. The port-City interface: Trends, problems and examples. Geoforum, [s.I.], v. 20, n. 4, p.429-435, jan. 1989. Elsevier BV. http://dx.doi.org/10.1016/0016-7185(89)90026-2.

LI, Yongkui et al. Organizational Behavior in Megaprojects: Organizational Behavior in Megaprojects: Integrative Review and Directions for Future Research. Journal Of Management In Engineering, Reston, v. 35, n. 4, p.111, 18 mar. 2019.

LUNGO, Mario. (2005). Globalización, grandes proyectos y privatización de la gestión urbana. Urbano, v. 11), n. 8, p. 49-58, julho 2005 Disponível em: http://redalyc.uaemex.mx/pdf/198/19801107.pdf. Acesso em: 07 ago. 2019.

LUNGO, Mario; SMOLKA, Martin. Macroproyectos urbanos: desafíos para las ciudades latinoamericanas. Land Line Newsletter, Lincoln Institute, v. 14, n. 4, 2002.

MONIÉ, Frédéric. Globalização, modernização do sistema portuário e relações cidade/porto no Brasil. In: Silveira, M R. (org.). Geografia dos transportes, 
circulação e logística no brasil.São Paulo: Outras Expressões, pp. 229-330, 2011.

MONIÉ, Frédéric; VASCONCELOS, Flávia Nico. Evolução das relações entre cidades e portos: entre lógicas homogeneizantes e dinâmicas de diferenciação.

Revista Franco-Brasileira de Geografia, n. 15. 2012. Disponível em: https://journals.openedition.org/confins/7685?lang=pt. Acesso em: 18 maio 2015.

MONIÉ, Frédéric; VIDAL, Soraia Maria do S. C.. Cidades, portos e cidades portuárias na era da integração produtiva. Cidades, Portos e Cidades

Portuárias na Era da Integração Produtiva, Rio de Janeiro, v. 40, n. 6, p.945995, agosto 2006.

WORLD BANK. Independent Evaluation Group (Org.). Lessons from Land Administration Projects: A Review of Project Performance Assessments. New York: leg Category 1 Learning Product March 31,, 2016. 54 p.

ZANCHETTI, Silvio Mendes; SOMEKH, Nádia. Avaliação de grandes projetos urbanos: notas metodológicas sobre a análise de casos brasileiros. Anais do III Encontro Nacional da ANPARQ. São Paulo, 2014. Disponível em: https://www.anparq.org.br/dvd-enanparq-3/htm/Artigos/ST/ST-PCl-00504 zancheti.pdf. Acesso em: 03 ago. 2019.

ZANETTI, Valdir Zonta. Planos e Projetos: Reconstruir e Requalificar. In: Planos e Projetos Ausentes: Desafios e perspectivas da requalificação das áreas centrais de São Paulo. Faculdade de Arquitetura e Urbanismo de São Paulo, Universidade de São Paulo, 2005. p. 20-27.

\section{ANEXO I \\ REFERÊNCIAS PARA A TABELA DE REVITALIZAÇÕES PORTUÁRIAS INTERNACIONAIS}

AIVP - THE WORLDWIDE NETWORK OF PORT CITIES. Plan the city with the port: guide of good pratices. Le Havre: Aivp, 2015. 132 p. Disponível em: http://www.aivp.org/en/2019/05/30/plan-the-city-with-the-port-guide-of-goodpractices-2/. Acesso em: 10 ago. 2019.

BERGSLI, Heidi. Marseille et Oslo: des stratégies entrepreneuriales pour transformer le front de mer. Mediterranée: Revue geógraphique des pays méditerranéens. Provence, p. 77-83. jun. 2008. Disponível em: https://journals.openedition.org/mediterranee/2772\#quotation. Acesso em: 10 ago. 2019.

DAAMEN, Tom A.; VRIES, Isabelle. Governing the European port-city interface: institutional impacts on spatial projects between city and port. Journal of Transport Geography. Delft, p. 4-13. fev. 2013. Disponível em: https://www.sciencedirect.com/science/article/abs/pii/S0966692312000762?via \%3Dihub. Acesso em: 10 ago. 2019.

GIOVINAZZI, Orianna; MORETTI, Marta. Port Cities and Urban Waterfront:: Transformations and Opportunities. Temalab: journal of Mobility, Land Use and Environment. Naples, p. 57-64. mar. 2010. Disponível em: 
http://www.camerablu.unina.it/index.php/tema/article/view/urn:nbn:it:unina3515. Acesso em: 10 ago. 2019.

GÓMEZ, Maricarmen Tapia. El impacto sociocultural de las transformaciones en el puerto de Barcelona. Revista Transporte y Territorio, Buenos Aires, $n$. 12, p.16-29, 2015. Disponível em:

<http://revistascientificas.filo.uba.ar/index.php/rtt/article/view/1219/1181>. Acesso em: 05 ago. 2019.

MAGRINYÀ, Francesc; MAZA, Gaspar. Simulations of Barcelona: Urban Projects in Port Spaces (1981-2002). In: PETERSON, Marina; MCDONOGH, Gary W. (Org.). Global Downtowns. Philadelphia: University Of Pennsylvania Press, 2012. p. 65-90.

MAGRINYÀ, Francesc; MAZA, Gaspar. Tinglados de Bar-cel-ona: la incorporación de espacios del puerto a la ciudad (1981-2002). Scripta Nova: Revista electrónica de geografía y ciencias sociales, [s.i.], v. 9, n. 193, p.0-0, jul. 2005. Disponível em: <http://www.ub.edu/geocrit/sn/sn-193.htm>. Acesso em: 10 ago. 2019.

PONZINI, Davide. Bilbao Effects and Narrative Defects: A critical reappraisal of an Urban Rethoric. Working Papers Du Programme Villes \& Territoires. Milan, p. 1-17. 2010. Disponível em: http://blogs.sciences-po.fr/recherchevilles/files/2010/08/Ponzini-Bilbao-Effects-and-Narrative-Defects.pdf. Acesso em: 11 ago. 2019

SUTTON, Oliver. La remodelación de la Marina Port Vell de Barcelona: estudio de caso sobre el papel del City branding en el gobierno urbano. Revista Transporte y Territorio, Buenos Aires, n. 12, p.30-47, 2015. Disponível em: $<$ http://revistascientificas.filo.uba.ar/index.php/rtt/article/view/1220>. Acesso em: 05 ago. 2019.

URBED; VAN HOECK, MarCO. REGENERATION IN EUROPEAN CITIES: Making Connections: Case Study of Kop van Zuid, Rotterdam (The Netherlands). [s.i.]: Joseph Rowntree Foundation, 2007. 45 p. Disponível em: <http://urbed.coop/sites/default/files/Case\%20Study\%20for\%20Kop\%20Van\%2 0Zuid,\%20Rotterdam. pdf>. Acesso em: 10 ago. 2019.

\section{ANEXO II \\ REFERÊNCIAS PARA A TABELA DE REVITALIZAÇÕES PORTUÁRIAS NACIONAIS}

ARRUDA, Euler Santos. Porto de Belém do Pará: Origens, Concessão e Contemporaneidade. Curso de Mestrado do Programa de Pós-Graduação em Planejamento Urbano e Regional (IPPUR), Rio de Janeiro, 2003. Disponível em: https://fauufpa.files.wordpress.com/2016/01/eulersantosarruda.pdf. Acesso em: 2 ago. 2019.

BRASIL. Ministério da Infraestrutura. Projeto de Revitalização - Belém Porto Futuro. 13 jan. 2017. Disponível em:

canaldoservidor.transportes.gov.br/estudos-e-pesquisas/90-portos-páginainicial/5495-projeto-de-revitalização-belém-porto-futuro.html. Acesso em: 08 ago. 2019. 
BRASIL. Ministério do Desenvolvimento Regional. Obras do Porto Futuro, em Belém (PA). 2017. Disponível em: www.mi.gov.br/ultimas-noticias/lasset_publisher/ZSVlyvx09vib/content/com-assinatura-do-contrato-obras-doporto-futuro-em-belem-pa-devem-comecar-em-fevereiro?inheritRedirect=false. Acesso em: 29 jul. 2019.

ESTAÇÃO DAS DOCAS. Pará 2000. Disponível em: www.estacaodasdocas.com.br. Vários acessos.

MENDONÇA, Adriana Santos. Grandes Projetos Urbanos e Gestão Pública: A Renovação da Área Portuária do Recife. Universidade Federal do Pernambuco, Recife, 2014. Disponível em: https://repositorio.ufpe.br/bitstream/123456789/17743/1/AdrianaSantosMendon ca Dissertacao UFPE CAC MDU 2014.pdf. Acesso em: 05 ago. 2019.

PONTE, Juliano Pamplona Ximenes. Cidade e água: Belém do Pará e estratégias de reapropriação das margens fluviais. Revista Arquitexto, Vitruvios, ano 08, jun. 2007. Disponível em:

www.vitruvius.com.br/revistas/read/arquitextos/08.085/237. Acesso em: 08 ago. 2019.

\section{PORTO DO RECIFE. Porto Novo: Projetos Porto Novo e Porto Novo}

Recife. Pernambuco, c201-?. Disponível em:

www.portodorecife.pe.gov.br/conheca_portonovo.php. Acesso em: 16 jul. 2019.

RIO DE JANEIRO. Lei Complementar n. ${ }^{\circ} 101$, de 23 de novembro de 2009. Modifica o Plano Diretor, autoriza o Poder Executivo a instituir a Operação Urbana Consorciada da Região do Porto do Rio e dá outras providências. Rio de Janeiro, 23 nov. 2009. Disponível em:

www.portomaravilha.com.br/conteudo/legislacao/LC101_-_23112009.pdf. Acesso em: 11 jul. 2019.

RIO DE JANEIRO. Projeto Porto Maravilha: a maior parceria públicoprivada do Brasil é da cidade do Rio. Rio de Janeiro, c201-. Disponível em: https://portomaravilha.com.br/uploads/revistas/e4a9a9faf91836f5c586225108b4 431a.pdf. Acesso em: 10 jul. 2019.

TAVARES, Amanda Gama; KIYOTANI, Ilana Barreto. Repercussões turísticas e sociais da revitalização de áreas portuárias - a Estação das Docas em Belém/PA. Revista de Turismo Contemporânea (RTC), Natal, v. 1, n. 1, p. 18-37, jul./dez. 2013.

WERNECK, Mariana da Gama e Silva; NOVAES, Patrícia Ramos; JÚNIOR, Orlando Alves dos Santos. A estagnação da dinâmica imobiliária e a crise da operação urbana do Porto Maravilha. Observatório das Metrópoles, Informe crítico, 28 dez. 2018. Disponível em: observatoriodasmetropoles.net.br/download/informe_criseportomaravilha_2018. pdf. Acesso em: 15 jul. 2019. 